archives-ouvertes

\title{
Remittances and incentive to migrate: An epidemic approach of migration
}

\author{
Claire Naiditch, Agnès Tomini, Christian Ben Lakhdar
}

\section{To cite this version:}

Claire Naiditch, Agnès Tomini, Christian Ben Lakhdar. Remittances and incentive to migrate: An epidemic approach of migration. 2012. hal-00988946

\section{HAL Id: hal-00988946 https://hal.univ-lille3.fr/hal-00988946}

Preprint submitted on 9 May 2014

HAL is a multi-disciplinary open access archive for the deposit and dissemination of scientific research documents, whether they are published or not. The documents may come from teaching and research institutions in France or abroad, or from public or private research centers.
L'archive ouverte pluridisciplinaire HAL, est destinée au dépôt et à la diffusion de documents scientifiques de niveau recherche, publiés ou non, émanant des établissements d'enseignement et de recherche français ou étrangers, des laboratoires publics ou privés. 


\section{Document de travail}

- [2012-7]

"Remittances and incentive to migrate: An epidemic approach of migration"

Claire Naiditch, Agnes Tomini and Christian Ben Lakhdar

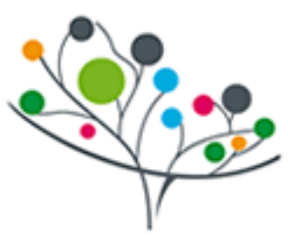

Université Lille Nord de France

Pole de Recherche

et dEnselgnement Superieur 


\title{
Remittances and incentive to migrate: An epidemic approach of migration
}

\author{
Claire Naiditch, Agnes Tomini and Christian Ben Lakhdar
}

\section{Claire Naiditch}

PRES Université Lille Nord de France, Université Lille 1, Laboratoire EQUIPPE EA 4018, Villeneuve d'Ascq, France.

claire.naiditch@univ-lille1.fr

\section{Agnes Tomini}

PRES Université Lille Nord de France, Université Lille 1, Laboratoire EQUIPPE EA 4018, Villeneuve d'Ascq, France.

agnes.tomini@univ-lille1.fr

\section{Christian Ben Lakhdar}

LEM, Catholic University of Lille (FLSEG), 60 bd Vauban, Lille, France; christian.benlakhdar@icllille.fr 


\title{
Remittances and incentive to migrate: An epidemic approach of migration.
}

\author{
Claire Naiditch, $\quad$ Agnes Tomini ${ }^{\dagger} \quad$ and Christian Ben Lakhdar ${ }^{\ddagger}$
}

December 13, 2011

\begin{abstract}
Migrants' remittances should be considered as one of the determinants of migration flows, since they have an economic impact on recipient economies, and can play a signaling role concerning the actual economic conditions in countries. In both cases, the decision to migrate may be interpreted as the result of a "contagion" occurring through the receipt of remittances. We therefore use an "epidemic model" to formalize such mechanisms, and include these feedback effects in the migrants' dynamics. This model allows us to understand the role played by various parameters including this "contagion" factor in order to appraise the impact of different public policies on the total number of migrants.
\end{abstract}

JEL Classification: F22, F24, C61, C62

Keywords: Migration, Remittances, Epidemic Modeling, Dynamic Analysis

\footnotetext{
${ }^{*}$ EQUIPPE, University Lille 1, FSES, Cité scientifique, 59655 Villeneuve d'Ascq Cedex, France ; claire.naiditch@univ-lille1.fr.

${ }^{\dagger}$ EQUIPPE, University Lille 1, FSES, Cité scientifique, 59655 Villeneuve d'Ascq Cedex, France ; agnes.tomini@univ-lille1.fr.

${ }^{\ddagger}$ LEM, Catholic University of Lille (FLSEG), 60 bd Vauban, Lille, France ; christian.benlakhdar@icllille.fr.
} 


\section{Introduction}

Migration is considered as one of the defining global issues of the early twenty-first century, as more and more people are on the move today than at any other point in human history 11 There are now between 192 and 216 million people living outside their place of birth (IOM, 2011; Ratha et al., 2011), which represents between 3 and 3.2 per cent of the world's population. This means that roughly one of every thirty-five persons in the world is a migrant.

As stated by Massey et al. (1993) in their survey of theories on international migration, at present, there is no single, coherent theory of international migration. Concerning economic theories, neoclassical economics explain migration as an individual decision aiming at maximizing income. The main determinants of migration flows are then the differential between the economic situations in the home and host countries, and migration costs (Sjaastad, 1962; Todaro, 1969; Harris \& Todaro, 1970). The new economics of labour migration, in contrast, considers migration as a household decision in order to minimize risks on family income or overcome familial credit constraints (Mincer, 1978; Stark, 1991). Both theories have incorporated the role played by previous migrants in shaping migration flows, through the friends and relatives effect (or network effect). Most empirical studies do not distinguish between households and individuals, when studying the determinants of migration flows. They emphasize the role of push and pull factors ${ }^{2}$ (incomes, education levels, unemployment, inequalities, poverty... in host and home countries) in shaping migration flows. Other factors, often used in gravity models, have been put forward: geographical (distance between source and host countries, common land border...), cultural (common language, common colonial past...) and demographic (share of young population in the origin country) factors. Finally, two other factors play a significant role in explaining migration flows: the stock of previous migrants and migration policies (quotas, legalization programs...). Most of these studies focus on migration to the US and find that the previous factors have different quantitative impacts on migration flows, depending on the period studied and the data used (see Borjas, 1987; Borjas and Bratsberg, 1996; Yang, 1995; Karemera et al., 2000; Hatton and Williamson, 2002; Clark et al., 2007; Hatton, 2010). Other papers study trends in UK net migration in the last decades (Hatton,

\footnotetext{
${ }^{1}$ See the International Organization for Migration website : http://www.iom.int/jahia/Jahia/aboutmigration/lang/en.

${ }^{2}$ Push factors are factors leading a person into leaving his home country, such as low income, high unemployment, lack of opportunities, natural and environmental disasters, war... On the other hand, pull factors concern attractive features of potential host countries, such as high income, low unemployment, better living conditions, political or religious freedom...
} 
2005) or focus on recent migration flows to OECD countries (Pedersen et al., 2006; Mayda, 2010).

Two criticisms can be made to these studies. First, they implicitly assume that potential migrants know with certainty the economic situation prevailing for migrants in the destination country. Second, they do not seem to pay attention to the role that remittances may play in shaping migration flows. However, over the years, migrants' remittances have become a major source of financing in the developing world: in 2009, remittance flows are estimated at US $\$ 416$ billion worldwide, US $\$ 307$ billion of which went to developing countries (Ratha et al., 2011). They constitute the second largest source of currencies for these countries, slightly behind foreign direct investments but before official development aid. Most empirical studies find that different migrants have different motives to remit, and that each migrant may remit to his family for several different reasons: altruism, exchange and investment, implicit familial arrangements (loan, insurance), or personal strategies (Rapoport \& Docquier, 2006); however, in the majority of cases, there is a part of altruism in the remitting decision. If the remitting decision has been studied carefully by economists, they have not considered the causal link between migration and remittances as thoroughly and this link is still subject to controversy. Migration is of course a necessary condition for remittances, but another question remains: do remittances have an impact on migration?

This question still has not found a clear-cut answer and our analysis aims to contribute to the debate in an original way. Taking into account the fact that people residing in their home country receive remittances and have only little information on the economic situation of migrants in the host country, we develop a new tool to study the link between remittances and migration. Remittances have an impact on migration through two different channels. First, remittances may act as a signal of the economic conditions of migrants and thus influence migration intention and decision. Second, remittances may have an impact on the economic conditions of recipients and may on migration incentives.

In both cases, the decision to migrate can be interpreted as the result of a "contagion" occurring through the receipt of remittances. Such mechanisms can be formalized by "epidemic models".

As indicated by their name, epidemic models were originally designed in order to understand the spread of infectious diseases. Bernouilli (1766) was the first one to model a smallpox epidemic in order to evaluate the risk-benefit of inoculating the disease (which was the vaccinating method back then). Nowadays, epidemic models are still largely used 
in public health studies, for instance to study HIV epidemics (Isham, 1988), the spread of obesity (Gonzalez-Parra et al., 2010) or nosocomial diseases (Temime, 2010). These models aim at evaluating not only the infection natural progression, but also different public policies which could be used to slow down or even stop its diffusion.

Epidemic models are also used to study various topics not related to health and diseases. Criminology, economics, marketing and finance now use epidemic models. For instance, Behrens et al. (1999) develop a " $L H$ model" to describe the epidemics of illicit drugs. They define two categories of users with opposite impacts on initiation ${ }^{3}$ They use this model to show that drug treatment's effectiveness depends critically on the stage in the epidemic in which it is employed; reducing the number of heavy users in the early stages of an epidemic can be counterproductive if it masks the risk of drug use $4^{4}$

In economics, the diffusion of technological or organizational innovations has been widely studied using epidemic models. Mansfield (1961) is one of the first to model the process of the adoption of innovations as a function of the extent of the dissemination of information on these innovations. The contaminant factor is the information spreading between firms, from those that have already adopted the innovation to those getting in touch with the former. The "infectious" characteristic depends on the technology characteristics such as its profitability, its risk and the size of the necessary investment. Several marketing studies studying the purchasing behavior of certain goods and hence their diffusion follow the same line of reasoning (see Mahajan \& Muller, 1979). Finally, in finance, epidemic models are used to highlight the herding behavior of some securities buyers. Social interactions and information stemming from these interactions act as a contaminant factor, influencing the behavior of potential buyers or sellers on the market. Hong, Kubik \& Stein (2005) study the behavior of mutual funds managers and show that their decision to buy or sale securities fit an epidemic model where social interactions between managers are the contaminant factor.

To the best of our knowledge, migration has not yet been studied using epidemic modeling with remittances as a "contaminating factor", even though some studies on migrants' remittances suggest that migration intentions and decisions may be based on received remittances. In other words, we propose here to develop an epidemic model extending

\footnotetext{
${ }^{3}$ More precisely, they distinguish between light users $(L)$ whose feedback on the initiation of non-users is positive (festive consumption), and heavy users $(H)$ whose feedback on initiation is negative (since their poor health condition sends a negative advertisement for the drug).

${ }^{4}$ Rydell, Caulkins \& Everygham (1996) also use an epidemic model to reach different conclusions. They show that, when fighting against illicit drugs, implementing a strong enforcement policy at the outset of an epidemic of psychoactive substance consumption is highly efficient to reduce its expansion. However, when the epidemic has already widely disseminated, enforcement policies are of little use whereas treatment policies, minimizing sanitary costs linked to substance uses, begin to be efficient.
} 
migration models, either by "endogeneizing" the perception of the economic conditions in the destination country, thanks to the signal given by remitted amounts or by taking into account the economic impact of remittances.

We distinguish between the two different channels through which remittances impact migration. In both cases, various forces play opposite roles, such that some push residents into migrating whereas others discourage individuals. The first channel considers the informative role of remittances: high remittances, signaling a successful migration, generate incentives to migrate (by improving the expectations attributed to migration) while low remittances (or even the absence of remittances), perceived as a failed migration, consequently create disincentive to migrate (by deteriorating the expectations attributed to migration). On the other hand, the second channel takes into account the economic role of remittances: high remittances, fulfilling residents' perceived needs for income and insurance, create disincentives to migrate (there is no need for additional members to emigrate) while low remittances are insufficient to cover recipients' needs but may help them cover migration costs $5^{5}$, and thus facilitate additional migration (to help satisfying needs in the home country).

In the model, we divide migrants into two populations according to the level of remittances and we analyze how both groups vary across time. Their evolution obviously depends on the link between remitters and recipients but also on other factors such as the probability to economically succeed in the host country or exogenous disappearing rates. The impacts of all these factors are finally studied in order to yield some policy implications.

The paper is organized as follows. The next section presents some stylized facts on migration and remittances and the different impacts of remittances on migration highlighted in the literature. Section 3 introduces the epidemic model. The existence, stability properties of the equilibrium and the local effects of the model parameters on the steady state are studied separately for the two channels, in Sections 4 and 5. The results of the model are discussed in terms of public policies in Section 6. The final section concludes the paper.

\footnotetext{
${ }^{5}$ Potential migrants may be constrained by their poverty and this credit constraint is likely to be relaxed by received remittances (see Hatton \& Williamson, 2002).
} 


\section{Theoretical background and stylized facts}

As explained in the introduction, the discussion about migration determinants remains crucial within the migration literature. Most studies have concentrated on perceived differences, e.g. on differences in economic opportunities or political situation, between source and host countries. However, they implicitly assume that migrants have perfect information on the economic situation abroad and thus, they have neglected the powerful influence of remittances in giving information about the true situation of migrants in the destination country and in changing migration incentives. A few papers only study the potential impact of remittances on migration: some scholars suggest that remittances have a positive impact on migration while others suggest that the link between remittances and migration is negative.

Remittances actually contribute to increase the income of left home family members; then, if large enough, they can discourage additional household members to migrate (van Dalen et al., 2005). A negative link between migration and remittances is also put forward by Stark (1995). He works out an imperfect information model, with high and low productivity migrants, whose productivities cannot be observed directly by would-be employers in the foreign country. Hence highly productive migrants would send remittances home to low productivity workers in order to prompt them to stay.

Nevertheless, this body of literature is not really convincing because remittances are only appraised like another source of income. In effect, we can venture a guess that, since the level of remittances actually sent by migrants is very high, it should be large enough to negatively impact migration intentions and decisions. As long as remittances reduce the income differential between origin and destination countries, individuals should be discouraged to move.

However, even if remittances contribute to improve the economic situation at home, it is far from clear that they actually decrease migrations. A perusal observation of the 2011 factbook published by the World Bank (Ratha et al., 2011) even shows that most of the top remittance-receiving countries in 2010 are also top emigration countries. In 2010, Mexico has the largest outflow of emigrants (11.9 millions), and is the third remittancereceiving country (with 22.6 US\$ billions received). As concerned migration, it is followed by India (11.4 millions of emigrants) which is the largest recipient of remittances (55 US\$ billions). The correspondence between these two rankings can be emphasized by studying the Chinese case. China reaches the fourth rank as concerned migration (8.3 millions of emigrants) and the third place among the top remittance-receiving countries (with 51 
US $\$$ billions received). Figure 1 outlines that there exists a positive correlation between emigration and remittances in 20106

Figure 1: The link between the number of emigrants and remittances

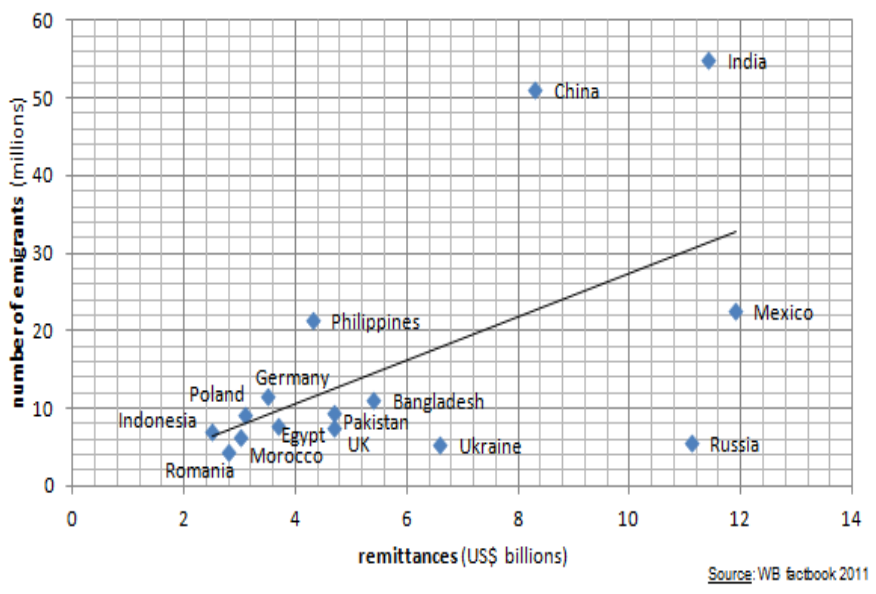

Several determinants could explain this trend. The network theory suggests that wouldbe migrants are sensitive to the help provided by previous migrants, who have precious information on the host country and share the same culture or language (see Beine et al., 2011). Remittances may represent the existence of a migrant network. However, migration remains a complex process, making tough the identification of all of its determinants; remittances may explain part of population migrations through the information on the destination country that they vehicle.

Remittances can be interpreted as signals of the actual and not the perceived financial attractiveness of destination countries and thus, trigger chain migration. Remittances can thus induce recipients into migrating if they are seen as revealing the success of the migrant in the host country (van Dalen et al., 2005). Others have argued that this positive relationship between remittances and migration can be obtained in a loan repayment model, where the migrant committed himself to reimburse his family who paid for the up-front cost of migration, and to help other family members migrate in the future (Ilahi \& Jafarey, 1999). In a different set-up, Stark \& Wang (2002) analyze a problem where skilled

\footnotetext{
${ }^{6}$ This relation is also observed when using data from the 2008 World Bank factbook (Ratha \& Xu, 2008). The three top remittance-receiving countries, India, China and Mexico (respectively with 27, 25.7 and 25 US $\$$ billions received), also belong to the top emigration countries. Namely, Mexico copes with the largest population outflow with 11.5 millions of emigrants and India and China are respectively the third and the fourth emigration countries with respectively 10 and 7.3 billions of emigrants.
} 
and unskilled migrants are partially complementary inputs; hence skilled workers' wages increase with the number of unskilled workers. Then skilled migrants may decide to remit to unskilled workers, in order to attract them to the host country; remittances are then sent in the purpose of inducing the migration of unskilled residents. Finally, building a model of migratory equilibria, Naiditch \& Vranceanu (2010) show that when remittances are invested in the home country of migrants, they are also positively related to migration.

Beyond these theoretical approaches, the few empirical studies on the link between migration and remittances find that receiving remittances has a positive impact on migration intentions, at least in Morocco (van Dalen et al., 2005), Bosnia-Herzegovina (Dimova \& Wolff, 2009), Fiji and Tonga (Leeves, 2009) and Eastern Europe and Central Asia countries (Naiditch \& Vranceanu, 2010).7] The signaling effect of remittances seems to be the main factor behind this result.

\section{The epidemic model}

The model describes the link between migrants who remit to their families back home, and recipients who have to choose between staying in their home country or migrating to the host country. Remittances may influence migration decision: they can be seen as a signal about the economic situation of people who have already moved away from their home country and they contribute to the income of recipients still in their origin country. Both elements represent the core of our model.

\subsection{The migrant's income and remittances}

The economic situation of migrants is approximately represented by their income in the host country, denoted by $y$. To keep the formalization as simple as possible, we assume that a migrant can either succeed economically and get the high income $y^{H}$, or fail economically and get the low income $y^{L}$, with $y^{L}<y^{H}$. This income is representative of one migrant's type (failing or successful).

We intuitively assume that when a migrant first enters the host country, he earns the low income $y^{L}$. In the next period, if he stays in the host country, his income increases to $y^{H}$ with probability $p$ (exogenous) or remains the same with probability $1-p$. We

\footnotetext{
${ }^{7}$ Note that most studies on the link between remittances and migration use cross-sectional data, and study the impact of remittances on migration intentions and not on migration decisions. According to Epstein \& Gang (2006), migration intentions provide an upper bound on the number of realized migration. These studies also come across the problem of disentangling migration intentions and migration opportunities. Indeed, remittances may have an impact on migration intentions as well as migration constraints, since they can help relax the budget constraint of recipients and potential migrants.
} 
assume that once the migrant has economically succeeded (i.e. he earns the income $y^{H}$ ), his situation cannot deteriorate: as long as he is in the host country, he will keep earning the high income $y^{H[8}$

At each time period, the migrant decides whether or not he remits to his family, and how much he remits. We assume that the migrant remits for altruistic motives $9^{9}$ his utility increases with the utility of the recipients. We also assume that remittances are a normal good. Then, a successful migrant chooses an optimal amount $T^{H}$ of remittances higher than the optimal amount $T^{L}$ of a failing migrant (in case of perfect information) 10

\subsection{The migrant population}

Depending on their level of income, the migrant population $M_{t}$ can be divided into two groups: those who economically succeeded and remit a high amount $T^{H}$, and those who economically failed and remit a low amount $T^{L}$. These two groups are respectively called the high remitter population (or the successful migrants) and the low remitter population (or the failing migrants) and denoted by $H_{t}$ and $L_{t}$. Thus, at period $t$, the total number of migrants is $M_{t}=L_{t}+H_{t}$.

Both groups vary across time because of various reasons, including the link between migrants who remit and recipients remaining in the home country. First, at each time period, some migrants in both groups "disappear" for exogenous reasons (return home, death...). We denote respectively by $a>0$ and $g>0$ the proportion of failing and successful migrants who disappear.

Second, at each time period, the stock of low remitters increases with a flow of new migrants $m_{t}$ (who earn the low income $y^{L}$ ). Simultaneously, some low remitters economically

\footnotetext{
${ }^{8}$ Alternatively, we could assume that some successful migrants, while still successful, may decide, after a while, to remit low amounts (because their attachment to their home country declines over time, see Brown, 1998). The parameter $p$ would then represent a "net probability of success".

${ }^{9}$ There are various motives for remitting, ranging from altruism to self-interest. See Rapoport \& Docquier (2006) for a literature review on motives to remit.

${ }^{10}$ Empirical evidence on the link between remittances and migrants' income is rather scarce. For instance, several empirical studies show that the elasticity of remittances to income is positive (Johnson \& Whitelaw, 1974; Lucas \& Stark, 1985; Hoddinott, 1994) while the proportion of income remitted may decrease (Johnson \& Whitelaw, 1974; Mohammad et al., 1973) or increase (Rempel \& Lobdell, 1978) with migrants' income. More recent papers study the link between remittances and the education level of migrants, which could be seen as a proxy of their income. Some find that the education level of migrants does not have a significant impact on remitted amounts (Rodriguez \& Horton, 1994; Naufal, 2008), while others show that more skilled migrants remit less (Faini, 2007; Niimi et al., 2008) and others find the opposite result (Bollard et al., 2011). The latter add that "the higher income earned by [skilled] migrants, rather than characteristics of their family situations, explains much of the higher remittances".
} 
succeed and become high remitters while some others disappear and some remain unsuccessful. Thus, at each period $t$, a flow of $m_{t}$ migrants enters the low remitter population, while a flow of $a L_{t}$ low remitters disappear and a flow of $(1-a) p L_{t}$ migrants quit the low remitter population to become high remitters (and $(1-a)(1-p) L_{t}$ low remitters keep the same income and remain in the low remitter population). Given all these observations, the law motion of the low remitter population can be formulated as follows:

$$
\dot{L}=m_{t}-[a+p(1-a)] L_{t}
$$

Symmetrically, the stock of high remitters increases with the flow of low remitters becoming high remitters and decreases with the flow of successful migrants disappearing. Thus, the law motion of the high-remitter population is given by:

$$
\dot{H}=p(1-a) L_{t}-g H_{t}
$$

Figure 2 sums up how both groups vary at each period.

Figure 2: Migrants' incomes and remittances at each period

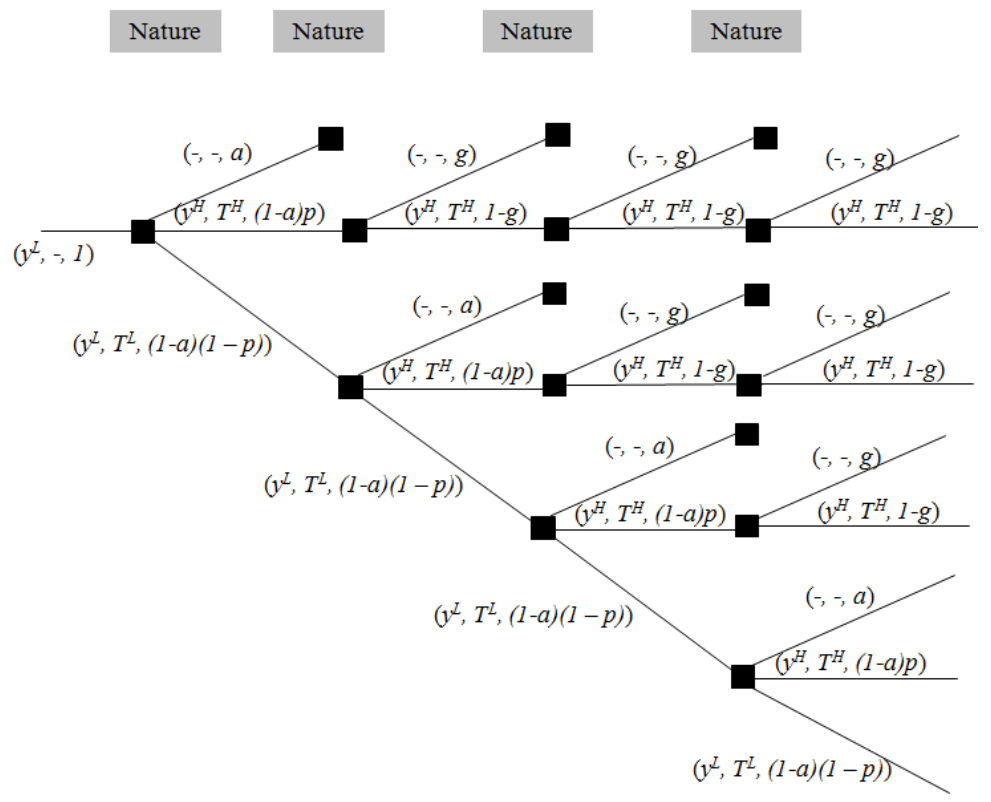

At each time period, there are $m_{t}$ new migrants; they earn the low income $y^{L}$. At period $t$, the $L(t)$ migrants who failed remit the low amount $T^{L}$. In the next period, these 
migrants disappear with probability $a$, become successful with probability $(1-a) p$, or keep the same low income in the host country with probability $(1-a)(1-p)$. Likewise, at period $t$, the $H(t)$ migrants who succeeded remit the high amount $T^{H}$. In the next period, these migrants disappear with probability $g$ or stay in the host country and keep the same high income with probability $(1-g)$.

\subsection{Incentives to migrate}

At each time period, people still residing in their origin country must decide whether to migrate to the host country or to stay in their home country. Each resident chooses his location in order to maximize his utility 11 The decision to migrate thus depends on the income of residents and on their expectations concerning migration. The latter depends on information received from migrants about their economic situation in the host country. We assume that the only information available to residents is migrants' remittances. More precisely, people still living in their origin country know how many migrants remit the high amount $T^{H}$ and how many remit the low amount $T^{L}$; residents know $H$ and $L$.

As seen in Section 2, theoretically the impact of remittances on migration can be either positive or negative. Thus, we need to distinguish between two different channels, according to the sign of this impact. This is done in the two following sections.

\section{The positive impact of remittances on incentives to migrate}

This section deals with the issue of the positive impact of high remittances on migration. In order to study the impact of remittances on migration through the informative channel, we first analyze the existence of a steady state(s) and investigate the stability properties before turning to comparative statics.

\subsection{High remittances as a contaminant factor}

Following the main conclusion of empirical studies (cf. Section 2), we first focus on the case where remittances have a positive impact on migration decision. In other words, this means that the flow of new migrants $m$ is positively related to the number of high remitters, $H$, because high remittances signal a successful migration. However, it is negatively

\footnotetext{
${ }^{11}$ Here, we assume that residents can only migrate to one host country, and do not compare different potential destination countries. This assumption relies on the fact that there is a strong concentration in international migration patterns, with a few large corridors accounting for a disproportionate share of the overall stock of migrants (Docquier et al., 2010). This could be partly explained by the large positive effect of diasporas on migration flows and stocks (Beine et al., 2011).
} 
related to $L$ because low remittances signal a failed migration. In that sense, we face a "behavioral epidemics" because high remitters stimulate (or "contaminate") residents into migrating whereas the presence of low remitters discourage them. The "recruitment" effect ${ }^{12}$ is therefore mitigated by the presence of low remitters. For instance, this deterrence effect of migrants remitting $T^{L}$ can depend on the relative number of failing migrants compared to the number of successful migrants.

In line with the formulation of Behrens et al. (1999), we assume that the number of new migrants $m_{t}$ is the sum of a constant exogenous number of residents who decide to migrate without being influenced by previous migrants' behavior, the innovators $i$, and the number of "contaminated" residents given by the "contagion" function $F(H, L)$ which summarizes the positive and negative incentive effects of migrants' behavior.

\section{Assumption 1}

(i) $F(H, L)$ is a function increasing in $H ; \partial F(H, L) / \partial H>0$.

(ii) $F(H, L)$ is a function decreasing in $L ; \partial F(H, L) / \partial L<0$.

We also introduce some boundary conditions in order to capture what happens when the high (resp. low) remitter population is very large, or at the opposite when there are no high (resp. low) remitters. In others words, this allows us to observe the size of the recruitment effect (resp. the deterrence effect) when the high (resp. low) remitter population is either large or small as well as the relative impact of the "recruitment" effect with respect to the deterrence effect when both groups are very large.

\section{Assumption 2}

(i) $\lim _{H \rightarrow 0} F(H, L)=0 ; \lim _{H \rightarrow+\infty} F(H, L)=+\infty$

(ii) $\lim _{L \rightarrow 0} F(H, L)=F(H, 0) \in \mathbb{R}^{+} ; \lim _{L \rightarrow+\infty} F(H, L)=0$.

(iii) $\lim _{(H, L) \rightarrow(0,0)} F(H, L)=0 ; \lim _{(H, L) \rightarrow(+\infty,+\infty)} F(H, L) \in \mathbb{R}^{+}$

Up to now, we can formulate the dynamic system including the characterization of the number of new migrants $m_{t}$.

$$
\begin{aligned}
\dot{H} & =p(1-a) L_{t}-g H_{t} ; H(0)=H_{0} \\
\dot{L} & =i+F\left(H_{t}, L_{t}\right)-[a+p(1-a)] L_{t} ; L(0)=L_{0}
\end{aligned}
$$

\footnotetext{
${ }^{12}$ Following the terminology of Behrens et al. (1999), high remitters "recruit" new migrants.
} 
with $H_{0}>0$ and $L_{0}>0$ the initial conditions.

Our model can be represented by Figure 3, with full arrows representing flows of individuals and dotted arrows flows of information.

Figure 3: The Flow Diagram

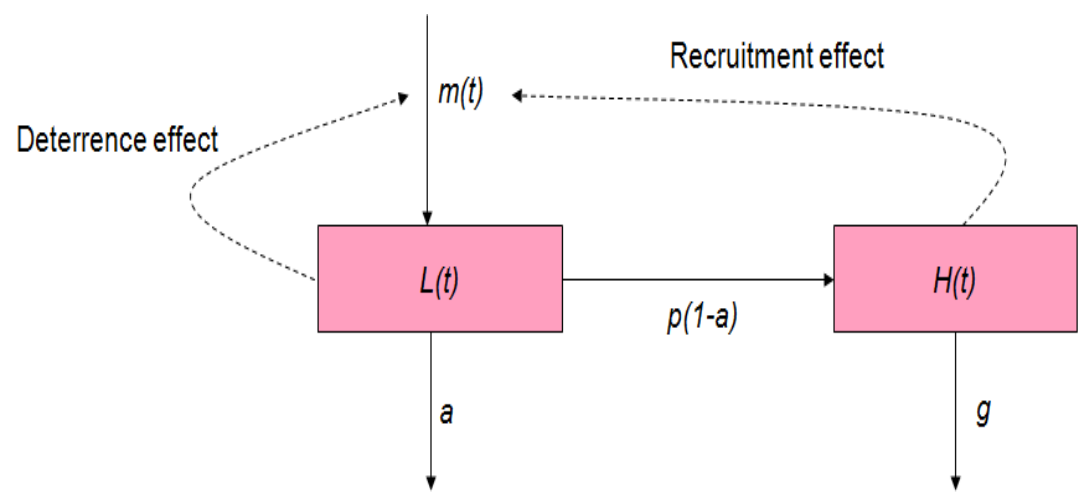

This formulation of the model allows us to understand how the "contagion" function stimulates or discourages the arrival of new migrants, and thus increases or decreases the population of both groups beyond.

It is straightforward to see that an increase in the number of high remitters will accelerate the increase of the low remitter population because the attractiveness effect will be stronger: $\frac{d \dot{L}}{d H}=\frac{\partial F\left(H_{t}, L_{t}\right)}{\partial H_{t}}>0$ under assumption 1 .

The impact of an increase in the number of low remitters on the variation of this same group is not so obvious since several forces play opposite roles via the "contagion" function. On the one hand, an increase in the number of low remitters reinforces the deterrence effect which decreases migration incentives and thus the number of new migrants which, in turn, decreases the number of low remitters. Moreover, as the number of low remitters grows, the number of migrants exiting this group (because they disappear for exogenous reasons or become successful) increases as well. On the other hand, an increase in the number of low remitters will raise the number of high remitters in the long run, which in turn will increase the "recruitment" effect and thus the number of new migrants, increasing the low remitter population. It is credible to assume that the forces leading to a decline in the low remitter population are stronger than the one leading to an increase of that population through an increase in the "recruitment" effect. Assumption 3 summarizes these comments. 
Assumption $3 \frac{d \dot{L}}{d L}=\frac{\partial H}{\partial L} \cdot \frac{\partial F\left(H_{t}, L_{t}\right)}{\partial H_{t}}+\underbrace{\frac{\partial F\left(H_{t}, L_{t}\right)}{\partial L_{t}}-[a+p(1-a)]}_{\equiv C}<0$

Assumption 3 thus consists in comparing the increase in the "recruitment" effect, $\frac{\partial H}{\partial L} \cdot \frac{\partial F\left(H_{t}, L_{t}\right)}{\partial H_{t}}$, which contributes to increase the low remitter population to a negative term representing the increase in the deterrence effect linked to a rise in the low remitter population and the probability to quit this group (disappearing or becoming successful), $C \equiv \frac{\partial F\left(H_{t}, L_{t}\right)}{\partial L_{t}}-[a+p(1-a)]$, with $C<0$ under assumption 1. Assumption 3 implies that $C<\frac{\partial H}{\partial L} \cdot \frac{\partial F\left(H_{t}, L_{t}\right)}{\partial H_{t}}$.

\subsection{Existence and stability of the equilibrium}

A steady state, if it exists, is investigated by setting the time derivatives of equation (3) and (4), respectively, to zero. From equation (3), the steady state of the high remitter population can be computed as a function of the low remitter population:

$$
H_{t}^{*}=\frac{p(1-a)}{g} L_{t}^{*}
$$

The number of high remitters, at the steady state, is proportional to the number of low remitters, with a proportionality ratio equal to the probability of low remitters to become high remitters over the disappearing rate of high remitters.

Setting equation (4) to zero and using equation (5), we obtain the steady state for the low remitter population:

$$
i+F\left(\frac{p(1-a)}{g} L_{t}^{*}, L_{t}^{*}\right)-[a+p(1-a)] L_{t}^{*}=0
$$

We define the function $\phi\left(L_{t}\right) \equiv i+F\left(\frac{p(1-a)}{g} L_{t}, L_{t}\right)-[a+p(1-a)] L_{t}$. Then, the steady state for the low remitter population is the solution of the following equation:

$$
\phi\left(L_{t}^{*}\right)=0
$$

On the basis that the steady state of the high remitter population depends linearly on the low remitter population, investigation of the existence of a steady state can be reduced to the study of condition (7).

Proposition 1 Under assumptions 2 and 3 , there exists a unique stationary equilibrium. 
Proof. See appendix.

Now, we examine the local dynamics of the system. We have to study the characteristic roots of the linearized system. On the basis of the two-equations system (3) and (4), we form the Jacobian matrix and evaluate it at the steady state point $\left(L^{*}, H^{*}\right)$.

$$
J=\left(\begin{array}{ll}
\frac{\partial \dot{H}}{\partial H} & \frac{\partial \dot{H}}{\partial L} \\
\frac{\partial \dot{L}}{\partial H} & \frac{\partial \dot{L}}{\partial L}
\end{array}\right)_{\left(L^{*}, H^{*}\right)}=\left(\begin{array}{cc}
-g & p(1-a) \\
\frac{\partial F(\cdot)}{\partial H} & C
\end{array}\right)_{\left(L^{*}, H^{*}\right)}
$$

with $C=\frac{\partial F(\cdot)}{\partial L}-[a+p(1-a)]<0$.

The signs of the trace $\operatorname{Tr}(J)$, the determinant $\operatorname{det}(J)$ and the discriminant $\Delta(J)$ of the jacobian matrix give information about stability properties of the steady state.

\section{Proposition 2}

(i) For any $\left(L^{*}, H^{*}\right)$, the steady state is a node.

(ii) The characteristic roots $\lambda_{1,2}$ are both negative, which means that both populations, the high remitters and the low remitters trajectory, converge to the stable equilibrium $\left(L^{*}, H^{*}\right)$ in the long-run.

Proof. See appendix.

Proposition 2 shows that, for any initial number of high remitters and low remitters, all trajectories of the two populations flow towards the steady state.

\subsection{Comparative statics}

This subsection investigates the comparative statics of the model, which shows the local impact on the steady state of marginal changes in the disappearing rate of low remitters $(a)$, the disappearing rate of high remitters $(g)$ and the probability that a low remitter becomes a high remitter (the probability of success $p$ ).

In a first step, we analyze the impact of one of the three parameters $x=\{a, g, p\}$ on the low remitter population from equation (7). Since we know that $\phi(L, x)$ is such that $\phi(L, x)=0$ and that its first derivative with respect to $L$ is strictly negative, we know that there exists a function $L=\varphi(x)$. We can therefore use the implicit function theorem to deduce the sign of $\frac{d L}{d x}=\varphi^{\prime}(x)$. Formally, we know that: 


$$
\frac{d L}{d x}=-\frac{\frac{\partial \phi(L, x)}{\partial x}}{\frac{\partial \phi(L, x)}{\partial L}}, \text { with } \frac{\partial \phi\left(L^{*}, x\right)}{\partial L}<0
$$

Therefore, the sign of the impact of an incremental increase in one parameter on the low remitter population at the steady state is given by the sign of the impact of an increase in that parameter on the function $\phi(L, x)=0$. That is:

$$
\operatorname{sign}\left(\frac{d L}{d x}\right)=\operatorname{sign}\left(\frac{\partial \phi(L, x)}{\partial x}\right)
$$

The second step consists in studying the impact of an incremental increase in one of these same three parameters on the high remitter population. From equation (5), we observe that the high remitter population is a function of $L$ and implicitly of $x, H(L(x), x)$. Therefore, we compute its derivative as follows:

$$
\frac{d H(\cdot)}{d x}=\frac{\partial H(\cdot)}{\partial L} \cdot \frac{d L}{d x}+\frac{\partial H(\cdot)}{\partial x}=\frac{p(1-a)}{g} \frac{d L}{d x}+\frac{\partial H}{\partial x}
$$

The sign of this derivative thus depends on the impact of each parameter on both the low remitter population, $\frac{d L}{d x}$, and the high remitter population, $\frac{\partial H}{\partial x}$. The result is unambiguous if $\frac{d L}{d x}$ and $\frac{\partial H}{\partial x}$ are of the same sign.

In particular, we find that the impact on the high remitter population steady state $H^{*}$ of the disappearing rate of $L, a$, and of the disappearing rate of $H, g$, is straightforward because these parameters negatively impact the low remitter population and the high remitter population. However, the effect on the low remitter population of changes in the probability of success, $p$, is quite ambiguous. Yet, by computation, we observe that an increase in that probability increases the high remitter population.

The combination of the effects on both populations, the low and high remitter populations, allows us to conclude on the variations of the total migrant population.

All these observations can be summarized in the following proposition.

Proposition 3 An incremental change in various parameters of the model $-a, g$ and $p$ - affects the populations of low and high remitters and the total population of migrants as follows: 
- The low remitter population $\left(L^{*}\right)$ decreases with higher disappearing rates of low and high remitters ( $a$ and $g$ ). However, if the attractive effect of high remitters, at the margin, is higher (resp. lower) than their disappearing rate, then the probability of becoming a high remitter (p) has a positive (resp. negative) impact on the low remitter population at the steady state.

- The high remitter population $\left(H^{*}\right)$ decreases with higher disappearing rates of low and high remitters ( $a$ and $g$ ). However, their number increases with a higher probability of success ( $p$ ).

- The migrant population $\left(M^{*}\right)$ decreases with higher disappearing rates of low and high remitters ( $a$ and $g$ ). However, if a higher probability of success ( $p$ ) increases the low remitter population, then an increase in this probability also increases the total migrant population. In the reverse case, the number of migrants can increase or decrease according to the various forces of both disappearing rates, the deterrence and the attractive effects.

Proof. See appendix.

Table 1 presents all these results:

Table 1: Comparative Statics

\begin{tabular}{cccc} 
& $d L / d x$ & $d H / d x$ & $d M / d x$ \\
\hline \hline disappearing rate of $\mathrm{L}$ & - & - & - \\
disappearing rate of $\mathrm{H}$ & - & - & - \\
probability to become $\mathrm{H}$ & $+/-$ & + & $+/-$ \\
\hline
\end{tabular}

\section{The negative impact of remittances on incentives to migrate}

This section turns to the second channel through which remittances impact migration and corresponds to the literature claiming that remittances may negatively affect motivations to migrate. Contrary to the first channel, we identify different types of equilibrium depending on ranges of parameter values corresponding to various dynamic behaviors. For the sake of clarity, we chose to focus on the analysis of steady states and comparative statics not analogue to the first case rather than to study all the different equilibriums, which could turn out to be wordy. 


\subsection{High remittances as deterrence effect}

When considering the economic role of remittances, we assume that the flow of new migrants, $m$, is negatively related to the number of high remitters, $H$, whereas the number of low remitters, $L$, stimulates people living in their origin country into migration. For instance, when recipients receive a high amount from abroad, their income actually increases which, in turn, decreases their motivations to migrate for economic reasons. On the other hand, residents receiving low amounts still have incentives to send another member of the household abroad (because their needs are not satisfied) and may use the remittances to finance migration costs.

Consequently, the properties of the "contagion" function differ from those introduced in the previous channel. Here, the "recruitment" effect is captured by the presence of low remitters $(L)$ whereas the deterrence effect is linked to the number of high remitters $(H)$. On this basis, assumption 4 summarizes the corresponding properties of the function $F$.

\section{Assumption 4}

(i) $F(H, L)$ is a decreasing function in $H ; \partial F(H, L) / \partial H<0$.

(ii) $F(H, L)$ is an increasing function in $L ; \partial F(H, L) / \partial L>0$.

We also reverse the boundary conditions in order for them to fit this new channel.

\section{Assumption 5}

(i) $\lim _{H \rightarrow 0} F(H, L)=F(0, L) \in \mathbb{R}^{+} ; \lim _{H \rightarrow+\infty} F(H, L)=0$

(ii) $\lim _{L \rightarrow 0} F(H, L)=0 ; \lim _{L \rightarrow+\infty} F(H, L)=+\infty$.

(iii) $\lim _{(H, L) \rightarrow(0,0)} F(H, L)=0 ; \lim _{(H, L) \rightarrow(+\infty,+\infty)} F(H, L) \in \mathbb{R}^{+}$

Despite these new properties of the "contagion" function, assumption 3 nevertheless remains true in the sense that, following a marginal increase in the low remitter population, the forces leading to a decline in the low remitter population are assumed to be stronger than those increasing the group in the long run. This assumption remains credible since the population of low remitters cannot indefinitely increase. However, the new properties of the "contagion" function imply a slightly different interpretation. Indeed, we now compare 
a direct effect of an increase in the low remitter population, which is the increase in the "recruitment effect" $\partial F(H, L) / \partial L$ net of the full proportion of low remitters who quit the group, $a+p(1-a)$, to an indirect effect represented by the increase in the deterrence effect linked to an increase in the number of high remitters due to the initial increase in the number of low remitters, $\frac{\partial H}{\partial L} \cdot \frac{\partial F\left(H_{t}, L_{t}\right)}{\partial H_{t}}$. Note that the sign of $C=\frac{\partial F\left(H_{t}, L_{t}\right)}{\partial L_{t}}-[a+p(1-a)]$ is now ambiguous and depends on the parameters. Assumption 3 only implies that $C<$ $\underbrace{-\frac{\partial H}{\partial L} \cdot \frac{\partial F\left(H_{t}, L_{t}\right)}{\partial H_{t}}}_{\equiv C_{0}}$.

\subsection{Existence and stability of the equilibrium}

The analysis of the existence and the stability of the steady state is quite similar to the one conducted in Section 4. However, a perusal investigation of the stability properties shows that the equilibrium can be of different types according to the values of parameters.

Since the dynamic system formed by the two equations (3) and (4) has exactly the same structure for both channels, the steady state of low and high remitters, if it exists, is also the same:

$$
H_{t}^{*}=\frac{p(1-a)}{g} L_{t}^{*} \quad \phi\left(L^{*}\right)=i+F\left(\frac{p(1-a)}{g} L_{t}^{*}, L_{t}^{*}\right)-[a+p(1-a)] L_{t}^{*}=0
$$

Given the new properties of the "contagion function", we easily observe that the sign of the trace of the Jacobian matrix (equation 8 ) is now ambiguous and can either be positive or negative. Even if the sign of the determinant does not change (it is still positive), the discriminant may also be of various signs. Therefore, the full analysis of the properties of the equilibrium leads us to identify four different cases according to four different ranges of the parameters values ${ }^{13}$ Each range leads to specify various types of equilibrium. Namely, these various types of equilibrium depend on the value of the direct effect on the low remitter population of the arrival of an additional low remitter $(C=\partial F(\cdot) / \partial L-a-p(1-$ a)). According to its value, the dynamic system behaves differently.

Proposition 4 Under assumptions 35, we claim that:

(i) there exists a unique steady state,

(ii) this equilibrium can be either a sink (stable node/focus) or a source (instable node/focus) depending on the values of the parameters of the model.

\footnotetext{
${ }^{13}$ These four cases are presented in the appendix of proposition 4
} 
Proof. See appendix.

Table 2 summarizes the different types of equilibrium of the model for a particular range of $C \in]-\infty, C_{0}[$.

Table 2: Equilibrium Types

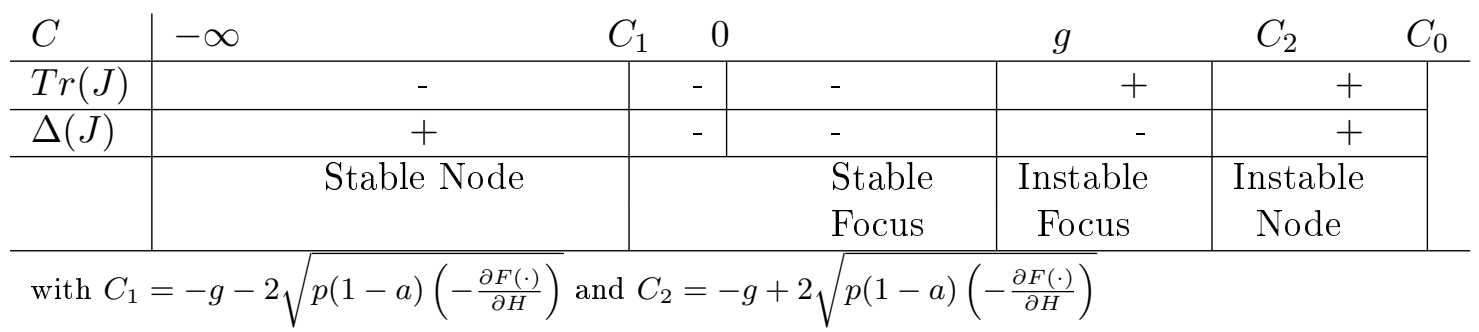




\subsection{Comparative statics}

Like previously, we conduct the comparative statics analysis to study the local impact on the steady state of marginal changes in one of the three parameters $(a, g, p)$.

The ambiguity of signs does not allow us to conclude easily on the impact of a variation in one of the parameters on the steady state. Nevertheless, the ranges of parameter values allow us to obtain some relevant results outlined in proposition 5

Proposition 5 A marginal variation in parameters - a, $g, p$-impacts the populations of low and high remitters and the total population of migrants in the long run as follows:

- The low remitter population $\left(L^{*}\right)$ can rise or fall with higher disappearing rates of low remitters (a) but increases with higher disappearing rates of high remitters ( $g$ ). On the contrary, the number of low remitters decreases with a higher probability of success ( $p$ ).

- The high remitter population $\left(H^{*}\right)$ decreases with higher disappearing rates of low remitters (a) as long as the net effect on "recruitment" of a marginal increase in the number of low remitters $(C)$ is smaller than the probability to remain a low remitter $((1-a)(1-p))$; otherwise, it increases with a. This population, at the steady state, decreases with higher disappearing rates of high remitters $(\mathrm{g})$ as long as the net effect on "recruitment" of a marginal increase in the number of low remitters $(C)$ is negative and rises otherwise. Finally, the probability to succeed (p) has a positive impact on the population equilibrium if and only if the disappearing rate of low remitters (a) is higher than the marginal increase in the "recruitment" effect $(\partial F(\cdot) / \partial L)$.

- The migrant population $\left(M^{*}\right)$ can either increase or decrease with higher disappearing rates of low remitters (a) as well as with higher disappearing rates of high remitters $(g)$ when the net effect of a marginal increase in the number of low remitters on "recruitment" is negative $(C<0)$. However, with positive values, the total population of migrants increases with higher disappearing rates of high remitters $(\mathrm{g})$. Finally, the impact of a higher probability of success remains ambiguous when the net effect on "recruitment" is small enough $(C<-p(1-a))$ whereas it is negative otherwise.

Proof. See appendix.

Table 3 sums up the results of proposition 5 
Table 3: Comparative Statics in Scenario 2

\begin{tabular}{|c|c|c|c|c|c|c|c|c|}
\hline$C$ & & & $-p(1-a)$ & & & $(1-a)(1-p)$ & $g$ & $C_{2}$ \\
\hline \multirow{3}{*}{$\begin{array}{l}\text { Disapparing } \\
\text { rate of } L\end{array}$} & $d L / d a$ & $+1-$ & $+/-$ & $+/-$ & $+1-$ & $+1-$ & $+/-$ & $+/-$ \\
\hline & $d H / d a$ & - & - & - & - & + & + & + \\
\hline & $d M / d a$ & $+/-$ & $+/-$ & $+/-$ & $+/-$ & $+/-$ & $+/-$ & $+/-$ \\
\hline \multirow{3}{*}{$\begin{array}{l}\text { Disappearing } \\
\text { rate of } H\end{array}$} & $d L / d g$ & + & + & + & + & + & + & + \\
\hline & $d H / d g$ & - & - & - & + & + & + & + \\
\hline & $d M / d g$ & $+/-$ & $+/-$ & $+/-$ & + & + & + & + \\
\hline \multirow{3}{*}{$\begin{array}{c}\text { Probability } \\
\text { to become } \\
H\end{array}$} & $d L / d p$ & - & - & - & - & - & - & - \\
\hline & $d H / d p$ & + & - & - & - & - & - & - \\
\hline & $d M / d p$ & $+1-$ & - & - & - & - & - & - \\
\hline
\end{tabular}

\section{Discussion and policy implications}

Previously, the comparative statics revealed how, for both channels, a variation in one of the three parameters of the model $(a, g$ or $p$ ) affects the steady state equilibrium, in other words the populations of low and high remitters. We now turn to a discussion related to policy implications deriving from these results. These parameters may be modified by public policies implemented either in the host country or in the origin country of migrants. Therefore, a good understanding of the impact of a change in one of these parameters and the channels of the diffusion of these impacts may be helpful to policy-makers.

The disappearing rate of failing migrants $(a)$ represents the proportion of low remitters who quit this population but do not become high remitters. These migrants may leave that group for several reasons. They can go back to their home country voluntarily ${ }^{14}$ or simply die 15 But the level of the disappearing rate of low remitters can also reflect specific public policies directed towards migrants: policies to facilitate migrants' returns to their home country, difficulties to renew residence permits and visas, deportations of illegal migrants...

For both channels, an increase in the disappearing rate of low remitters has a direct negative impact on the low remitter population as well as on the high remitter population, since the number of successful migrants depends positively on the flows from failing migrants to successful ones: the less low remitters there are, the less high remitters there will be (remember that we assume that new migrants automatically join the failing migrants population).

\footnotetext{
${ }^{14}$ They could also go to another country than their home country.

${ }^{15}$ Note that the mortality rate of failing migrants may be higher than the mortality rate of natives of the host country or even than that of the high remitter population. Indeed, failing migrants may have strenuous jobs, benefit from worse health insurances, live in poor conditions...
} 
However, a change in this variable also indirectly affects the "contagion" function and thus has different implications depending on the prevailing channel. Recall that, in the first channel, high remittances act as a contaminant factor, and, in the second channel, low remittances play that role. An increase in the disappearing rate of low remitters induces a direct decrease in the low remitter population, which implies a smaller (resp. higher) deterrence effect in the first (resp. second) channel. Simultaneously, the increase in the disappearing rate of low remitters induces a direct decrease in the high remitter population, which implies a smaller (resp. higher) recruitment effect in the first (resp. second) channel. In both cases, the deterrence and the recruitment effects vary in the same direction, but have opposite consequences on the number of new migrants and ultimately in the number of low remitters.

The final impact of the disappearing rate of low remitters on the number of low and high remitters and on the total migrant population is negative in first channel, as shown in proposition 3 , and remains ambiguous in the second one, as shown in proposition 5.

The disappearing rate of high remitters $(g)$ is in part similar to the disappearing rate of low remitters since it also represents returns and deaths. However, some successful migrants may leave the high remitter population while staying in the host country: the disappearing rate $g$ also includes migrants who stop remitting.

For both channels, an increase in the disappearing rate of high remitters has a direct negative impact on the high remitter population. This decrease in the number of high remitters, either because they actually left the host country or because they stopped remitting, has indirect consequences on the "contagion" function: it has a negative impact on the recruitment effect in the first channel, while the impact is positive in the second channel. Thus, the number of new migrants and ultimately of low remitters decreases in the first channel while it increases in the other one.

The fall (resp. rise) in the number of low remitters in the first (resp. second) channel, in turn, has a negative (resp. positive) impact on the high remitter population. Thus, in the first channel, the direct and indirect impacts of an increase in the disappearing rate of high remitters on that same population reinforce each other: the number of high remitters decreases with their disappearing rate. However, in the second channel, these impacts vary in opposite directions, which explains why proposition 5 states that the high remitter population may increase with its own disappearing rate, depending on parameters values.

Finally, in the first channel, the total number of migrants decreases with the disappearing rate of high remitters (since both remitter populations decrease as well). In the second channel, depending on the parameters values, the variation of the total number of migrants with the disappearing rate of high remitters depends on the parameters values. 
Given these mechanisms, the disappearing rate of high remitters may be targeted by policy-makers in order to influence migration flows. The impacts of policy changes on the number of migrants are straightforward if the first channel prevails; however, they are more difficult to anticipate in the second channel.

We will focus here on the case where high remittances are the contaminant factor. First, policy-makers can have a direct impact on the number of migrants by increasing both disappearing rates, through the implementation of policies facilitating migrants' returns to their origin countries or making more difficult their staying in the host country (policies concerning the renewal of visas, policies reducing labor access...). Second, policies influencing indirectly the rate of disappearance of successful migrants may be implemented. For instance, a successful migrant has a higher probability of beneficiating from the familyreunification policy; once his family has joined him in the host country, he may stop sending remittances since all the former beneficiaries now live with him! Naturalization policies may have the same indirect consequence: a successful migrant has a higher probability of being naturalized, in which case he may feel that he does not have anymore obligations to send money back to his origin country. This kind of policy therefore affects the disappearing rate by increasing the share of high remitters who "exit" from this population. Acknowledging the negative impact of a rise in the disappearing rate of high remitters on the migrant population, policy-makers can expect that these policies will decrease the number of migrants in the long run 16 .

The probability of leaving the low remitter population to join the high remitters one $(p)$ is quite difficult to precisely define. It is naturally linked to the host country labor market and reveals a probability of succeeding economically and socially. Therefore, measuring that probability and analyzing its causes remains a tricky question.

Nevertheless, propositions 3 and 5 yield some relevant indications about the impact of a variation of that probability by comparing the various forces in action.

First, an increase in the probability of success has a direct negative impact on the low remitter population and a direct positive impact on the number of high remitters on both channels.

Second, the variations in both populations have indirect impacts on the "contagion" function: in the first channel, these variations imply a decrease in the deterrence effect and an increase in the recruitment effect while it is the exact opposite in the second channel. Anyway, in both channels, the recruitment and deterrence effects vary in opposite directions

\footnotetext{
${ }^{16}$ We acknowledge the fact that information sent by those who return, by those who die or by those beneficiating from family-reunification policies may be different; in this model, however, they are treated as similar since we analyze the remitting behavior of migrants.
} 
and thus have similar consequences on the number of new migrants and ultimately on the low remitter population. The indirect impact of an increase in the probability of success is thus positive for both populations of remitters in the first channel and negative in the second. In the first channel, the direct and indirect impacts reinforce each other (positively) in the case of the high remitter population whereas they are contradictory for the low remitter population, which explains the results of proposition 3 . Likewise, in the second channel, the direct and indirect impacts reinforce each other (negatively) in the case of the low remitter population whereas they are contradictory for the high remitter population, which explains the results of proposition 5

The impact of the probability of success on the total population of migrants is ambiguous as well. Obviously, if the low and high remitter populations move in the same direction when this probability increases (both populations would increase in the first channel, and decrease in the second), then the impact on the total migrants population is straightforward (positive in the first channel, negative in the second). In the opposite case, the impact on the total number of migrants of an increase in the probability of success depends on the parameters values. More precisely, in the first schannel, in order to assess the impact of the probability of success on the total number of migrants, we need to compare two differentials: on the one hand, the difference between the disappearing rate of low remitters and their deterrence effect which represents the positive "exiting" rate of low remitters (those who disappear and the would-be migrants who did not migrate because of the deterrence effect); on the other hand, the difference between the disappearing rate of high remitters and their attractive effect which represents the positive "exiting" rate of high remitters (those who disappear minus the migrants who decided to come because of the attractive effect). If the first differential is higher than the second, then low remitters exit more "rapidly" than high remitters; the increased attractive effect induced by an increase in the probability of success is higher than the increased deterrence effect, and the total number of migrants increases with the probability of success. In the opposite case, the probability of success has a negative impact on the total migrant population.

Despite these ambiguous impacts, some policies directed towards migrants in host countries (affirmative action policies, training policies...) will necessarily have an impact on their probability of success and ultimately on migration flows. For instance, when high remittances are the contaminant factor (i.e. when the informative channel prevails), if public policies are such that the disappearing rate of successful migrants is high (through numerous family reunifications or naturalization for instance) and the disappearing rate of failing migrants low, then increasing the probability of success of migrants may surprisingly induce a fall in the total number of migrants. 
The analysis of the comparative statics and the discussion of their policy implications highlight that each of the main parameters of the model can directly be used as a migration tool to influence migration flows. Furthermore, our model allows us to shed light on how these same parameters also play an important role through another channel, namely the contagion function. By directly impacting the high and low remitter populations, these parameters modify the attractiveness and the deterrence effects such that the impact of a change in one of these variables goes beyond traditional beliefs.

\section{Conclusion}

In this paper, we developed an epidemic model in order to study migration incentives created by different levels of remittances revealing the success or the failure of migrants in the host country and having an impact on the economic conditions in the origin country of migrants. Remittances are seen as the "contaminant" factor for migration decisions.

This original approach allowed us not only to highlight the importance of dynamics when studying migration and the significance of some parameters such as the probability for a migrant to succeed economically in the host country, but also to draw some implications for public policies. And above all, we hope we demonstrated the benefit of epidemic models as promising avenue for research on the topic of migration and remittances.

In this paper, we distinguish between two channels through which remittances impact migration. In the first channel, remittances play an informative role about the actual economic conditions in the host country: high remittances, revealing the success of migrants, create incentives to migrate, while low remittances, revealing the failure of migrants, tend to dissuade would-be migrants. In the second channel, the economic impact of remittances is considered: high remittances, improving the economic conditions of recipients in their origin country, have a negative impact on migration intentions (and decisions), while low remittances do not fulfill recipients needs but can help financing additional migration and thus encourage further migration. In reality, of course, remittances play both roles: they have an impact on the economic conditions of recipients, and they give information about the host country. However, one of these impacts is likely to override the other, and the final impact of remittances on migration depends on the relative strength of each of these impacts. Thus, one may consider the study of the first channel as the case where the signaling role of remittances is more important than their economic impact, while the study of the second channel represents the inverse case.

The study of the comparative statics of the steady state equilibrium shows that, under certain conditions, family-reunification and naturalization policies may have the surpris- 
ing effect of reducing the total number of migrants in the host country, by diminishing incentives to migrate for would-be migrants still in their country of origin. Indeed, these policies indirectly increase the rate of "disappearance" of successful migrants by decreasing their motives to remit. When the signaling role of remittances overcomes their economic impact, this increase will reduce the attractive effect from migrants' remittances and thus total migration.

Likewise, policies improving the integration of migrants and thus their probability of success may have contradictory effects on the total number of migrants. These policies will induce an increase in the number of successful migrants if the signaling role of remittances is stronger than their economic impact, and a decrease in the number of failing migrants otherwise. However, their impact on the other remitter population and on the total migrant population can be either positive or negative, depending on other public policies influencing the rate of disappearance of migrants, and on the size of the attractive and deterring effects of high and low remitters. Thus, when designing policies directed towards migrants, host countries must acknowledge the fact that the behavior of migrants has an impact on future migration flows through the "contagion" function summing up the attractive and deterring effects of high and low remitters. Interactions between policies and their impacts on future migrations must be taken into account.

The epidemic modeling we proposed offers an interesting research agenda on the subject of migration and remittances. First, it allows us to overcome the empirical findings highlighted in the literature: the impact of remittances depends not only on their amounts but also on the probability for migrants to economically succeed in the host country. This probability was taken as exogenous in this model but future research could try to endogeneize it. Future research may also take into account the impact of returning migrants on migration incentives and acknowledge the fact that remittances may not reveal perfectly the economic conditions of migrants. Indeed, on the one hand, migrants may manipulate remitted amounts in order to improve their social status (Naiditch \& Vranceanu, 2011), or, on the other hand, they may be reluctant to send large amounts although they succeeded in the host country. Second, epidemic modeling allows us to study more thoroughly the impact on migration of changes in public policies aiming at managing migration, such as selected migration policies, family-reunification policies, borders controls...

Finally, epidemic models are intended to be empirically simulated. Regarding the relationship between remittances and migration incentives, empirical data necessary to provide comprehensive information to simulate our model and derive robust conclusions are lacking. For instance, there is no time series on the stock of migrants from one country residing in another one, not to mention the difficulty to estimate disappearing rates and 
the probability of success of migrants. This first theoretical approach of epidemic modeling is a plea for more efficient information systems and more diverse indicators on migration and remittances.

\section{References}

[1] Behrens, D.A., Caulkins, J.P., Tragler, G., Haunschmied, J.L., and Feichtinger, G. 1999. A dynamic model of drug initiation: implications for treatment and drug control. Mathematical Biosciences, 159, 1, pp. 1-20.

[2] Beine, Michel, Docquier, Frédéric, and Özden, Çağlar. 2011. Diasporas. Journal of Development Economics, 95, pp. 30-41.

[3] Bernoulli D. 1766. Essai d'une nouvelle analyse de la mortalité causée par la petite vérole. Mem Math Phy Acad Roy Sci Paris 1766. (English translation entitled 'An attempt at a new analysis of the mortality caused by smallpox and of the advantages of inoculation to prevent it' In Smallpox Inoculation: An Eighteenth Century Mathematical Controversy, Bradley L. Adult Education Department: Nottingham, 1971, 21).

[4] Bollard, Albert, McKenzie, David, Morten, Melanie and Rapoport, Hillel. 2011. Remittances and the Brain Drain Revisited: The Microdata Show That More Educated Migrants Remit More. World Bank Economic Review, 25, 1, pp. 132-156.

[5] Borjas, George J. 1987. Self Selection and the Earnings of Emigrants. American Economic Review, 77, pp. 531-553.

[6] Borjas, George, J., and Bratsberg, Bernt. 1996. Who Leaves? The Outmigration of the Foreign-Born. Review of Economics and Statistics, 78, 1, pp.165-176.

[7] Brown, Richard P. C. 1998. Do Migrants' Remittances Decline over Time? Evidence from Tongans and Western Samoans in Australia. The Contemporary Pacific, 10, 1, pp. 107-151

[8] Clark, Ximena, Hatton, Timothy J., and Williamson, Jeffrey G. 2007. Explaining U.S. Immigration, 1971-1998. The Review of Economics and Statistics, 89, 2, pp. 359-373.

[9] van Dalen, Hendrik P., Groenewold, George, and Fokkema, Tineke. 2005. The Effect of Remittances on Emigration Intentions in Egypt, Morocco and Turkey. Population Studies, 59, 3, pp. 375-392. 
[10] Dimova, Ralitza, and Wolff, François-Charles. 2009. Remittances and Chain Migration: Longitudinal Evidence from Bosnia and Herzegovina. IZA Discussion Papers 4083, Institute for the Study of Labor (IZA).

[11] Docquier, Frédéric, Marfouk, Abdeslam, Özden, Çağlar, and Parsons, Christopher R. 2010. Geographic, gender and skill structure of international migration. Report written for the Economic Research Forum.

[12] Epstein, Gil S., and Gang, Ira N. 2006. The Influence of Others on Migration Plans. Review of Development Economics, 10, 4, pp. 652-665.

[13] Faini, Riccardo. 2007. Remittances and the Brain Drain: Do More Skilled Migrants Remit More?. World Bank Economic Review, 21, 2, pp. 177-191.

[14] Gonzalez-Parra, Gilberto, Acedo, L., Villanueva Mico, R.- I. and Arenas, Abrahan J. 2010. Modeling the social obesity epidemic with stochastic networks. Physica A, 389, pp. 3692-3701.

[15] Harris, John R., and Todaro, Michael P. 1970. Migration, Unemployment and Development: A Two-Sector Analysis. American Economic Review, 60, 1, pp. 126-142.

[16] Hatton, Timothy J. 2005. Explaining trends in UK immigration. Journal of Population Economics, 18, pp. 719-740.

[17] Hatton, Timothy J. 2010. The cliometrics of international migration: A survey. Journal of Economic Surveys, 24, 5, pp. 941-969.

[18] Hatton, Timothy J., and Williamson, Jeffrey G. 2002. What Fundamentals drive World Migration?. CEPR Discussion Paper 3559, Centre for Economic Policy Research, London, UK.

[19] Hoddinott, John. 1994. A Model of Migration and Remittances applied to Western Kenya. Oxford Economic Papers, 46, pp. 459-476.

[20] Hong, H., Kubik, J.D., and Stein, J.C. 2005. Thy neighbor's portfolio: word-of-mouth effects in the holdings and trades of money managers. Journal of Finance, 60, 6, pp. 2801-2824.

[21] Ilahi, Nadeem, and Jafarey, Saqib. 1999. Guestworker Migration, Remittances and the Extended Family: Evidence from Pakistan. Journal of Development Economics, 58 , pp. $485-512$. 
[22] IOM, 2011. International Organization for Migration website, http://www.iom.int/jahia/Jahia/about-migration/lang/en

[23] Isham, Valerie. 1988. Mathematical modeling of the transmission dynamics of HIV infection and AIDS: A review. Journal of the Royal Statistical Society, 151, 1, pp. $5-30$.

[24] Johnson, George E., and Whitelaw, W. E. 1974. Urban-Rural Income Transfers in Kenya: An Estimated-Remittances Function. Economic Development and Cultural Change, 22, 3, pp. 473-479.

[25] Karemera, David, Oguledo, Vitor I., and Davis, Bobby. 2000. A Gravity Model Analysis of International Migration to North America. Applied Economics, 32, pp. 17451755 .

[26] Leeves, Gareth. 2009. Migration Plans and Received Remittances: Evidence from Fiji and Tonga. International Migration Review, 43, 1, pp. 160-177.

[27] Lucas, Robert E.B., and Stark, Oded. 1985. Motivations to Remit: Evidence from Botswana. Journal of Political Economy, 93, 5, pp. 901-918.

[28] Mahajan, V., and Muller, E. 1979. Innovation diffusion and new product growth models in marketing. Journal of Marketing, 43, pp. 55-68.

[29] Mansfield, E. 1961. Technical change and the rate of imitation. Econometrica, 29, 4, pp. 741-766.

[30] Massey, Douglas S., Arango, Joaquim, Hugo, Graeme, Kouaouci, Ali, Pellegrino, Adela, and Taylor, Edward J. 1993. Theories of International Migration: A Review and Appraisal. Population and Development Review, 19, 3, pp. 431-466.

[31] Mayda, Anna Maria. 2010. International migration: A panel data analysis of the determinants of bilateral flows. Journal of Population Economics, 23, pp. 1249-1274.

[32] Mincer, J. 1978. Family Migration decisions. Journal of Political Economy, 86, 5, pp. 749-773.

[33] Mohammad, A., Butcher, Walter R., and Gotsch, C.H. 1973. Temporary Migration of Workers and Return Flow of Remittances in Pakistan. Economic Development Reports 234, Center for International Affairs, Harvard University. 
[34] Naiditch, Claire, and Vranceanu, Radu. 2010. Equilibrium migration with invested remittances - The EECA evidence. European Journal of Political Economy, 26, pp. 454-474.

[35] Naiditch, Claire, and Vranceanu, Radu. 2011. Remittances as a social status signaling device. Research in Economics, 65, 4, pp. 305-318.

[36] Naufal, G. 2008. Why Remit? The Case of Nicaragua. IZA Discussion Paper No. 3276, Institute for Study of Labor, Bonn.

[37] Niimi, Yoko, Özden, Çaglar, and Schiff, Maurice. 2008. Remittances and the Brain Drain: Skilled Migrants do remit less!. ADB Economics Working Paper No. 126.

[38] Pedersen, P.J., Pytlikova, M., and Smith, N. 2006. Migration into OECD countries 1990-2000. In Parson and Smeeding (eds.): Immigration and the Transformation of Europe. Cambridge University Press.

[39] Rapoport, Hillel, and Docquier, Frédéric. 2006. The Economics of Migrants' Remittances. In: S.C. Kolm et J. Mercier-Ythier (Eds.), Handbook on the Economics of Giving, Reciprocity and Altruism, volume 2, chapter 17, pp. 1135-1198, North-Holland, Elsevier.

[40] Ratha, Dilip, and Xu, Zhimei. 2008. Migration and Remittances Factbook 2008. Development Prospects Group, World Bank (Eds.), Washington D.C.

[41] Ratha, Dilip., Mohapatra, S., and Silwal, A. 2011. Migration and Remittances Factbook 2011. Migration and Remittances Unit, World Bank (Eds.), Washington D.C. http://go.worldbank.org/QGUCPJTOR0.

[42] Rempel, Henry, and Lobdell, Richard A. 1978. The Role of Urban-to-Rural Remittances in Rural Development. Journal of Development Studies, 14, 3, pp. 324-341.

[43] Rodriguez, Edgard R., and Horton, Susan. 1994. International Return Migration and Remittances in the Philippines. In: D. O'Connor and L. Farsakh (Eds.), Development Strategy, Employment and Migration. Country Experiences, OECD Development Centre, Paris.

[44] Rydell, C. P., Caulkins, J.P., and Everygham, S.S. 1996. Enforcement or treatment: Modeling the relative efficacy of alternatives for controlling cocaine. Operations Research, 44, 6, pp. 687-695. 
[45] Sjaastad, Larry A. 1962. The Costs and Returns of Human Migration. Journal of Political Economy, 70, 5, Part 2: Investment in Human Beings, pp. 80-93.

[46] Stark, Oded. 1991. The Migration of Labor. Basil Blackwell, Cambridge.

[47] Stark, Oded. 1995. Altruism and Beyond: An Economic Analysis of Transfers and Exchanges within Families and Groups. Cambridge University Press, Cambridge.

[48] Stark. Oded, and Wang, You Qiang. 2002. Migration Dynamics. Economic Letters, 76, pp. 159-164.

[49] Temime, Laura. 2010. Modélisation de la transmission des infections en milieu hospitalier. Médecine/Sciences, 26, pp. 205-207.

[50] Todaro, Michael P. 1969. A Model of Labor Migration and Urban Unemployment in Less Developed Countries. American Economic Review, 59, 1, pp. 138-148.

[51] Yang, P.Q. 1995. Post-1965 immigration to the United States. Praeger, Westport, Connecticut. 


\section{Appendix}

\section{Proof of proposition 1}

We have to check that $\phi\left(L_{t}\right)$ admits at least one solution. First, under assumption 2 we observe that:

$$
\lim _{L \rightarrow 0} \phi(L)=i \quad \lim _{L \rightarrow+\infty} \phi(L)=-\infty
$$

Under assumption 3 , we also observe that the function $\phi$ is monotonous:

$$
\phi^{\prime}(L)=\frac{p(1-a)}{g} \frac{\partial F(\cdot)}{\partial H}+\frac{\partial F(\cdot)}{\partial L}-[a+p(1-a)]<0
$$

Since $\phi(L)$ is strictly decreasing from $i$ to $-\infty$, there is a unique $L^{*}$ such that $\phi\left(L^{*}\right)=0$.

\section{Proof of proposition 2}

First, observe that:

$$
\begin{aligned}
\operatorname{Tr}(J) & =-g+\frac{\partial F(\cdot)}{\partial L}-[a+p(1-a)]=-g+C<0 \text { under assumption } 1 \\
\operatorname{det}(J) & =-g\left(\frac{\partial F(\cdot)}{\partial L}-[a+p(1-a)]\right)-p(1-a) \frac{\partial F(\cdot)}{\partial H} \\
& =-g\left(C+\frac{p(1-a)}{g} \frac{\partial F(\cdot)}{\partial H}\right)>0 \text { under assumption } 3 \\
\Delta(J) & =(\operatorname{Tr}(J))^{2}-4 \operatorname{det}(J)=\left(-\frac{\partial F(\cdot)}{\partial L}+[a+p(1-a)]-g\right)^{2}+4 p(1-a) \frac{\partial F(\cdot)}{\partial H} \\
& =(C+g)^{2}+4 p(1-a) \frac{\partial F(\cdot)}{\partial H}>0 \text { under assumption 1 }
\end{aligned}
$$

(i) The sign of the discriminant determines which kind of critical point we have. Since the discriminant is positive, we can conclude that the critical point is a node.

(ii) The sign of the trace gives information about stability. Since the trace is negative, we conclude that the system is stable. Since the determinant represents the product of the characteristic roots and the trace is the sum of characteristic roots, the characteristic roots $\lambda_{1,2}$ are of the same sign and are negative. The system converges to the steady state. 


\section{Proof of proposition 3}

In order to determinate the sign of $\frac{d L}{d x}$, we need to study the sign of $\frac{d \phi(L, x)}{d x}$. Let us compute the derivatives of interest for the low remitter population and use assumption 1

$$
\begin{aligned}
& \frac{\partial \phi\left(L^{*}, x\right)}{\partial a}=-L^{*}\left[\frac{p}{g} \cdot \frac{\partial F(\cdot)}{\partial H}+(1-p)\right]<0 \text { therefore } \frac{\partial L^{*}}{\partial a}<0 \\
& \frac{\partial \phi\left(L^{*}, x\right)}{\partial g}=-\frac{p(1-a) L^{*}}{g^{2}} \frac{\partial F(\cdot)}{\partial H}<0 \text { therefore } \frac{\partial L^{*}}{\partial g}<0 \\
& \frac{\partial \phi\left(L^{*}, x\right)}{\partial p}=\frac{(1-a) L^{*}}{g}\left(\frac{\partial F(\cdot)}{\partial H}-g\right)>0 \text { if } \frac{\partial F(\cdot)}{\partial H}>g,(<0 \text { otherwise }) \\
& \text { therefore } \frac{d L}{d p}>0 \text { if } \frac{\partial F(\cdot)}{\partial H}>g,(<0 \text { otherwise })
\end{aligned}
$$

We easily compute the partial derivatives of the high remitter population with respect to $a$ and $g$ and conclude on the sign of equation 10 :

$$
\begin{aligned}
& \frac{\partial H}{\partial a}=-\frac{p}{g} L^{*}<0 \text { therefore } \frac{d H}{d a}<0 \\
& \frac{\partial H}{\partial g}=-\frac{p(1-a)}{g^{2}} L^{*}<0 \text { therefore } \frac{d H}{d g}<0
\end{aligned}
$$

Then, inserting equation $(9)$ in the derivative 10 and using assumptions 1 and 3 , we get:

$$
\begin{gathered}
\frac{d H}{d p}=\frac{p(1-a)}{g}\left[-\frac{\frac{(1-a) L^{*}}{g}\left(\frac{\partial F(\cdot)}{\partial H}-g\right)}{\frac{p(1-a)}{g} \frac{\partial F(\cdot)}{\partial H}+\frac{\partial F(\cdot)}{\partial L}-[a+p(1-a)]}\right]+\frac{(1-a)}{g} L^{*} \\
=\frac{(1-a) L^{*}}{g}\left[\frac{\frac{\partial F(\cdot)}{\partial L}-a}{\left.\phi^{\prime *}\right)}\right]>0
\end{gathered}
$$

Concerning the results on the total migrants population, it is obvious for the effect of parameters $a$ and $g$ because it is the sum of two negative impacts. However, the derivative of $\frac{d M}{d p}$ is as follows:

$$
\begin{aligned}
\frac{d M}{d p} & =\frac{\frac{(1-a) L^{*}}{g}\left(\frac{\partial F(\cdot)}{\partial H}-g\right)}{\left.\phi^{\prime *}\right)}+\frac{(1-a) L^{*}}{g}\left(\frac{\frac{\partial F(\cdot)}{\partial L}-a}{\left.\phi^{\prime *}\right)}\right) \\
& =\underbrace{-\frac{1}{\left.\phi^{\prime *}\right)} \cdot \frac{(1-a) L^{*}}{g}}_{>0}(\frac{\partial F(\cdot)}{\partial H}-g+\underbrace{a-\frac{\partial F(\cdot)}{\partial L}}_{>0})
\end{aligned}
$$

Therefore, we distinguish 3 cases:

1. If $\frac{\partial F(\cdot)}{\partial H}>g$ then $\frac{d M}{d p}>0$.

2. If $a-\frac{\partial F(\cdot)}{\partial L}>g-\frac{\partial F(\cdot)}{\partial H}>0$, then $\frac{d M}{d p}>0$. 
3. If $g-\frac{\partial F(\cdot)}{\partial H}>a-\frac{\partial F(\cdot)}{\partial L}>0$, then $\frac{d M}{d p}<0$.

\section{Proof of proposition 4}

(i) Cf. proof of proposition 1

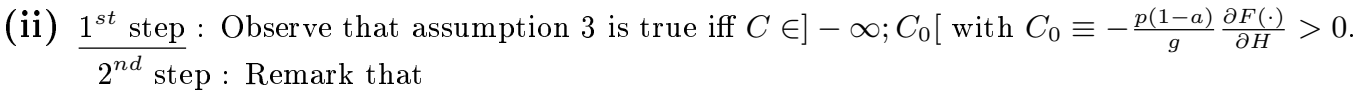

$$
\begin{aligned}
& \operatorname{Tr}(J)=-g+C<0 \text { if } C<g \text { (>0 otherwise) } \\
& \operatorname{det}(J)=-g\left(C-C_{0}\right)>0 \\
& \begin{aligned}
& \Delta(J)=(C+g)^{2}-4 p(1-a)\left(-\frac{\partial F(\cdot)}{\partial H}\right)=(C+g)^{2}-\left(2 \sqrt{p(1-a)\left(-\frac{\partial F(\cdot)}{\partial H}\right)}\right)^{2} \\
&=[C-\underbrace{\left(-g-2 \sqrt{p(1-a)\left(-\frac{\partial F(\cdot)}{\partial H}\right)}\right)}_{\equiv C_{1}}][C-\underbrace{\left(-g+2 \sqrt{p(1-a)\left(-\frac{\partial F(\cdot)}{\partial H}\right)}\right)}_{\equiv C_{2}}] \\
&\Delta(J)<0 \text { if } C \in] C_{1}, C_{2}[
\end{aligned}
\end{aligned}
$$

3rd step : Notice that

$$
\begin{aligned}
& \text { (a) } C_{0}-C_{2}=\left(2 \sqrt{g}-\operatorname{sqrtp}(1-a)\left(-\frac{\partial F(\cdot)}{\partial H}\right)\right)^{2}>0 \Rightarrow C_{0}>C_{2} \\
& \text { (b) } g-C_{2}=2\left(g-\sqrt{g C_{0}}\right) \\
& \text { if } g>C_{0} \Rightarrow g^{2}>g C_{0} \Rightarrow g>\sqrt{g C_{0}} \Rightarrow g>C_{2} \\
& \text { otherwise } C_{2}>g>0
\end{aligned}
$$

Combining the three steps, we identify 3 ranges of parameters in-between $C$ can vary.

1. Case $1: C_{0}>C_{2}>g>0>C_{1}$

2. Case $2: g>C_{0}>0>C_{2}>C_{1}$

3. Case $3: g>C_{0}>C_{2}>0>C_{1}$

\section{Proof of proposition 5}

We reformulate the proof of proposition 3 taking into account the new assumptions on the "contagion" function. 


$$
\begin{aligned}
& \frac{\partial \phi\left(L^{*}, x\right)}{\partial a}=-L^{*}\left[\frac{p}{g} \cdot \frac{\partial F(\cdot)}{\partial H}+(1-p)\right] \lesseqgtr 0 \text { therefore } \frac{d L}{d a} \text { ambiguous } \\
& \frac{\partial \phi\left(L^{*}, x\right)}{\partial g}=-\frac{p(1-a) L^{*}}{g^{2}} \frac{\partial F(\cdot)}{\partial H}>0 \text { therefore } \frac{d L}{d g}>0 \\
& \frac{\partial \phi\left(L^{*}, x\right)}{\partial p}=\frac{(1-a) L^{*}}{g}\left(\frac{\partial F(\cdot)}{\partial H}-g\right)<0 \text { therefore } \frac{d L}{d p}<0
\end{aligned}
$$

Then, inserting equation $(9)$ in the derivative 10 and using assumption 3 and assumption 4 , we get the result for $H$ :

$$
\begin{aligned}
& \frac{d H}{d a}=-\frac{p L^{*}}{g \phi^{\prime}\left(L^{*}\right)}\left(\frac{\partial F(\cdot)}{\partial L}-1\right) \Rightarrow \operatorname{sign}\left(\frac{d H}{d a}\right)=\operatorname{sign}(C-[(1-a)(1-p)]) \\
& \frac{d H}{d g}=-\frac{p(1-a)}{g^{2} \phi^{\prime}\left(L^{*}\right)} \cdot L^{*} \cdot C \Rightarrow \operatorname{sign}\left(\frac{d H}{d g}\right)=\operatorname{sign}(C) \\
& \frac{d H}{d p}=-\frac{(1-a) L^{*}}{g \phi^{\prime}\left(L^{*}\right)}\left(a-\frac{\partial F(\cdot)}{\partial L}\right) \Rightarrow \operatorname{sign}\left(\frac{d H}{d p}\right)=\operatorname{sign}(-C-p(1-a))
\end{aligned}
$$

We compute the derivatives of $L$ and $H$ to obtain the results of $M$ :

$$
\begin{aligned}
& \frac{d M}{d a}=-\frac{p L^{*}}{g \phi^{\prime}\left(L^{*}\right)}\left(\frac{\partial F(\cdot)}{\partial L}-\frac{\partial F(\cdot)}{\partial H}-1-\frac{g(1-p)}{p}\right) \Rightarrow \operatorname{sign}\left(\frac{\partial M}{\partial a}\right)=\operatorname{sign}\left(\frac{\partial F(\cdot)}{\partial L}-\frac{\partial F(\cdot)}{\partial H}-1-\frac{g(1-p)}{p}\right) \\
& \frac{d M}{d g}=-\frac{p(1-a) L^{*}}{g^{2} \phi^{\prime}\left(L^{*}\right)}\left(C-\frac{\partial F(\cdot)}{\partial H}\right) \Rightarrow \operatorname{sign}\left(\frac{\partial M}{\partial g}\right)=\operatorname{sign}\left(C-\frac{\partial F(\cdot)}{\partial H}\right) \\
& \frac{d M}{d p}=-\frac{(1-a) L^{*}}{g \phi^{\prime}\left(L^{*}\right)}\left(\frac{\partial F(\cdot)}{\partial H}-g-C-p(1-a)\right) \Rightarrow \operatorname{sign}\left(\frac{\partial M}{\partial p}\right)=\operatorname{sign}\left(\frac{\partial F(\cdot)}{\partial H}-g-C-p(1-a)\right)
\end{aligned}
$$




\section{Documents de travail récents}

- Nicolas Berman, Antoine Berthou and Jérôme Héricourt: "Export dynamics and sales at home" [2012-6]

- Muhammad Azmat Hayat, Etienne Farvaque: "Public Attitudes towards Central Bank Independence:Lessons From the Foundation of the ECB" [2012-5]

- Amandine Ghintran, Enrique Gonzales-Arangüena and Conrado Manuel : "A Probabilistic position value" [2011-4]

- Sophie Dabo-Niang, Anne-Françoise Yao : "Kernel spatial density estimation in infinite dimension" [2011-3]

- Xavier Chojnicki, Lionel Ragot: "Impacts of Immigration on Aging Welfare-State - An Applied General Equilibrium Model for France" [2011-2]

- Kirill Borissov, Stephane Lambrecht: "Education, Wage Inequality and Growth“ [2011-1] 